\title{
NATURAL HISTORY OF LEIOCEPHALUS SEMILINEATUS IN ASSOCIATION WITH SYMPATRIC LEIOCEPHALUS SCHREIBERSII AND AMEIVA LINEOLATA
}

Sonya E. Nelson ${ }^{1}$, Barb L. Banbury², Roland A. Sosa ${ }^{3}$, Robert Powell ${ }^{4}$, and John S. Parmerlee, Jr. ${ }^{4}$

${ }^{1}$ Department of Biology, Missouri Western State College, St. Joseph, MO 64507, USA

2 Museum of Natural History, University of Kansas, Lawrence, KS 66045, USA

3 Department of Biology, Loma Linda University, Riverside, CA 92515, USA

4 Department of Biology, Avila College, Kansas City, MO 64145, USA (powellr@mail.avila.edu)

Abstract. We examined diet, habitat use, and behavior (focal animal observations of intraspecific interactions, escape behavior, and activity period) of Leiocephalus semilineatus from near Puerto Alejandro, Provincia de Barahona, República Dominicana, and compared some parameters to similar data collected at a site near Baní, Provincia de Peravia. Leiocephalus semilineatus is found in sympatry in dry scrub forests at both sites with Ameiva lineolata, an active-foraging teiid of approximately the same size, and at the Puerto Alejandro site with a larger congener, $L$. schreibersii. Leiocephalus semilineatus and L. schreibersii from Puerto Alejandro exhibited sexual size dimorphism, whereas $L$. semilineatus from the Baní site and $A$. lineolata did not. Leiocephalus semilineatus spent most of the time motionless; other observed activities were interactions with conspecifics, movement, and feeding. Lizards were active from shortly after sunrise to sundown, although activity peaked in late morning. Mean cloacal temperatures of $L$. semilineatus did not differ significantly from those of the other two species, but were significantly above ambient temperatures. Reproductive condition of collected specimens was examined and no correlation was found between snout-vent length and egg, follicle, or testis size. Clutch size was 1-2. Diets consisted primarily of invertebrates and did not differ significantly between the three species. 
Members of the iguanian lizard genus Leiocephalus are ground-dwelling, sit-and-wait foragers endemic to the West Indies (Pregill, 1992). Ten of the 23 currently recognized species are found on Hispañiola (Powell et al., 1996). Leiocephalus

semilineatus (Figure 1), a Hispañiolan endemic, inhabits dry lowland habitats in the Culde-Sac Plain in Haiti and the Valle de Neiba and the Llanos de Azua in the República Dominicana, but may be absent from the eastern Valle de Neiba. This species has been found in dry and spiny scrub forest, open rocky terrain, along arroyos, and around garbage dumps. It is found primarily on the ground, usually perched on rocks, but sometimes in vegetation including dead agaves and small shrubs.

Several members of the genus Leiocephalus have been subjects of natural history studies, including Leiocephalus carinatus (Schoener et al., 1982), L. psammodromus (Smith, 1992, 1994, 1995; Smith and Iverson, 1993), L. schreibersii (Schreiber et al., 1993), and L. barahonensis (Micco et al., 1997), but little is known about the basic biology of $L$. semilineatus. Schwartz and Henderson (1991) described $L$. semilineatus as a xerophile associated with gravelly or rocky areas. In at least some parts of its range, Leiocephalus semilineatus is found in sympatry with the teiid Ameiva lineolata, an active forager of approximately the same body size, and with its larger congener, L. schreibersii. Because these areas of sympatry are ideal for studying niche partitioning, we examined aspects of the natural history of $L$. semilineatus and compared them to those of sympatric $L$. schreibersii and $A$. lineolata in order to evaluate the extent to which size of individual and foraging mode affect potentially competitive interactions.

\section{METHODS}

\section{Study Site}

The study was conducted from 29 May-14 June 1999 at a xeric site (Figure 2) between 1.7 and $3.0 \mathrm{~km}$ east of Canoa on the Puerto Alejandro road, Provincia de Barahona, República Dominicana. The site is in the rainshadow of the Sierra de Martín Garcia, rendering it particularly dry. Bimodal rainfall is characteristic of the area with a minor peak in late spring and a larger peak in late summer or fall (Salcedo et al., 1983). Weather fluctuates greatly during "rainy seasons" and occasional deviations from the expected hot, dry climate are linked to variations in the numbers and behaviors of animals encountered (e.g., Powell et al., 1996). Leiocephalus schreibersii is common in the area, most often seen in very open, sparsely vegetated sites. Ameiva lineolata was more rarely encountered, usually moving in scrubby areas.

We established eight $144 \mathrm{~m}^{2}$ plots for population estimates and used a $280 \mathrm{~m}$ section of road to observe activity and behavior. The section was generally bordered by berms of rocks and dirt, with intervening areas of variable habitats. The intervening areas included a sparsely vegetated flood plain bordered by rocky relief (to heights of about $10 \mathrm{~m}$ ), xeric clearings, and spiny scrub forest. Prominent vegetation included cholla (Opuntia caribaea), melon cactus (Melocactus communis), Cercus sp., Agave sp., and bunch grass (Danthonia domingensis). In slightly less xeric sections, such as along 
arroyos, trees such as mesquite (Prosopis juliflora), acacia (Acacia macracantha), and catalpa (Catalpa longissima) were common.

To compare diets in relation to foraging mode, we included data on Leiocephalus semilineatus and Ameiva lineolata that were collected on six previous trips to a xeric site near Baní, Provincia de Peravia (Powell et al., 1996), where L. schreibersii is not present. Post-preservation snout-vent lengths (SVLs) of all animals were measured to the nearest millimeter and used to calculate sexual size dimorphism (SSD) indices.

\section{Population Size Estimates}

To estimate population sizes of Leiocephalus semilineatus and L. schreibersii, we visited study plots for $20 \mathrm{~min} / \mathrm{d}$ between 0900 and 1200 for three consecutive days (Heckel and Roughgarden, 1979). We chose eight plots representing four abundant habitats: elevated rocky terrain, semi-vegetated rocky ground, rock pile and vegetationedged road, and shady arroyos. These were situated at least $200 \mathrm{~m}$ apart to minimize the likelihood of site-to-site migration. Leiocephalus are sit-and-wait foragers, are territorial, and have small home ranges (Jenssen et al., 1989). Paint guns (Heckel and Roughgarden, 1979) were used to mark all animals found within a plot boundary, using a different color each day. To eliminate the influence of differing activity periods for the species encountered, survey times were rotated throughout the morning. First time markings and re-markings were counted and used to calculate population size (Heckel and Roughgarden, 1979). The Schnabel (1938) method was used to confirm estimates.

Activity Period

To assess activity of Leiocephalus semilineatus, the same two individuals walked a 280 $\mathrm{m}$ transect hourly from 0645 and 1745 . This procedure was similar to those used in several other studies (e.g., Rand, 1964; Smith, 1994). Rand (1964) discussed potential biases of this method. To address these issues, data were collected on three nonconsecutive days. The transect was located along a road where lizards were often seen perched on rocks or foraging in the brush. The area was similar to two of the eight sampling plots, but not fully representative of the entire study site, as it included dirt and rock berms, spiny scrub, and ditches.

\section{Escape Behavior}

To assess approach distances and responses (Regalado, 1998), we approached individual lizards at a steady rate and recorded reactions in one of three categories: retreat into a burrow or crevice, movement to another perch, or movement into vegetation. If the lizard was still visible after an initial response, a secondary response upon subsequent approach was also noted. In each instance, we marked our exact location when the lizard reacted and measured the distance to the location of the lizard before it moved. 


\section{Focal Animal Observations}

Two or more observers recorded behavior (Altmann, 1974; Schreiber et al., 1993; Durtsche et al., 1997) from a distance of 2-6 $\mathrm{m}$ at the same time for $10 \mathrm{~min}$ intervals. Only when we prematurely lost sight of a lizard were observation periods shorter. We made focal observations only of animals that did not react to our presence.

We observed 37 Leiocephalus semilineatus for a total of $364 \mathrm{~min}$. We conducted focal observations from 0850 to 1430 , with the majority of observations (53\%) between 1130 and 1300 . Behavior was quantified by calculating the percent time spent motionless (perching), moving, interacting, and feeding. Perching included stillness and all nondisplay movements, such as tail movements, head tilting, body shifting, and substratelicking (activities that may have involved thermoregulation or surveys for the presence of potential competition, mates, or prey). Time spent moving included active foraging and shuttling between perches. We categorized display behaviors such as headbobs, pushups, and tail motions in response to the presence of other lizards as interactions. Feeding included only eating but not foraging, as the latter was often indiscernible from other movements.

Temperature

Following focal observations and estimates of population sizes, we collected Leiocephalus semilineatus and $L$. schreibersii by noosing or shooting with rubber bands. We took cloacal temperatures of animals immediately after capture with Fluke 50 Series thermometers with $\mathrm{K}$ type thermocouples (Fluke Corp. Everett, Washington). We also recorded substrate and air temperatures at points of capture. Animals were killed by lethal injection and preserved for later analyses of diet and reproductive condition. Specimens were deposited in the Bobby Witcher Memorial Collection (BWMC 6474-78, 6487-91, 6505-17), Avila College, Kansas City, Missouri.

\section{Reproduction}

We determined reproductive maturity of Leiocephalus semilineatus and $L$. schreibersii by the presence of enlarged testes in males and yolked ovarian follicles or oviductal eggs in females. We measured maximum lengths of these structures to the nearest $0.1 \mathrm{~mm}$ using calipers.

Diet

We excised stomachs from Leiocephalus semilineatus and $L$. schreibersii from the Puerto Alejandro site and from L. semilineatus and Ameiva lineolata from the Baní site. We categorized contents as invertebrate prey (identified to order or to family in the case of ants), plant material, or grit. We counted food items, determined their volume by fluid displacement (Milstead, 1957), and noted the frequency of occurrence to calculate importance values for each item (Powell et al., 1990; Howard et al., 1999). We used importance values to calculate niche breadths (Levins, 1968), 
standardized as in Hurlbert (1978), and dietary niche overlaps between species and among males, females, and juveniles within species (Pianka, 1973).

We used StatView II ${ }^{\text {TM }}$ (Abacus Concepts, Inc., Berkeley, California) for statistical analyses. Means are presented \pm one SE (except population size estimates, which are presented \pm one $S D$ ). For all statistical tests, alpha $=0.05$.

\section{RESULTS AND DISCUSSION}

\section{Body Size}

We collected 23 Leiocephalus semilineatus at the Puerto Alejandro site: ten adult females, eight adult males, and five juveniles/subadults. Mean adult male SVL was $45.8 \pm 1.2 \mathrm{~mm}(40-52 \mathrm{~mm})$ and that of adult females was $41.1 \pm 0.8 \mathrm{~mm}(36-44$ $\mathrm{mm})$. Mean juvenile/subadult SVL was $33.6 \pm 0.9 \mathrm{~mm}(31-36 \mathrm{~mm})$. Female and male $S V L$ differed significantly (Mann-Whitney $U, Z=-2.86, p=0.004$ ). According to these data, L. semilineatus exhibits SSD. The SSD index was 1.11 when based on mean sizes and 1.18 when based on maximum sizes (Roughgarden, 1995). We collected 40 L. semilineatus at the Baní site: 16 adult females, 16 adult males, and eight juveniles/subadults. Mean adult male SVL was $44.8 \pm 0.7 \mathrm{~mm}(\mathrm{n}=16,39-49 \mathrm{~mm})$, that of adult females was $43.3 \pm 0.5(n=16,40-48 \mathrm{~mm})$, and that of juveniles/subadults was $28.4 \pm 1.6(n=8,22-34 \mathrm{~mm})$. Male and female SVL did not differ significantly $(Z=-$ $1.44, p=0.15$ ). These data indicate a lack of SSD (indices $=1.03$, means; 1.02 , maxima).

We collected 37 Ameiva lineolata: ten adult females, 14 adult males, and 13 juveniles/subadults. Mean adult male SVL was $48.2 \pm 0.8(n=14,44-52 \mathrm{~mm})$, that of adult females was $46.9 \pm 0.8(n=10,44-51 \mathrm{~mm})$, and that of juveniles/subadults was $37.3 \pm 1.3(\mathrm{n}=13,28-42 \mathrm{~mm})$. Male and female SVL did not differ significantly $(Z=-$ $1.06, p=0.29$ ); no SSD is evident (SSD indices $=1.03$, means; 1.02 , maxima).

We collected 19 Leiocephalus schreibersii: 10 adult females, two adult males, and nine juveniles/subadults. Because we were interested in comparing diets of similarly sized animals, we collected primarily female and juvenile/subadult $L$. schreibersii, as they are most similar in size to $L$. semilineatus. Mean adult female SVL was $55.5 \pm 0.7 \mathrm{~mm}(\mathrm{n}=$ $10,52-59 \mathrm{~mm})$, that of adult males was $68.5 \pm 2.5 \mathrm{~mm}(\mathrm{n}=2,66-71 \mathrm{~mm})$, and that of juveniles/subadults was $35.9 \pm 1.5 \mathrm{~mm}(\mathrm{n}=9,31-43 \mathrm{~mm})$. The SVL of male and female $L$. schreibersii differed significantly $(Z=-2.16, p=0.031)$. Indices of SSD (1.23, means; 1.20, maxima) were as documented by Schreiber et al. (1993).

In order to place the varying SSD indices in the two populations of Leiocephalus semilineatus and the greater value for $L$. schreibersii into a broader context, we calculated SSD indices for all species of Leiocephalus presented by Schwartz and Henderson (1991) for which both male and female SVL were available. Within the genus, SSD indices were positively correlated with size (Spearman test, $n=21, Z=$ $2.34, p=0.019$ ). As a relatively large species, $L$. schreibersii has a high SSD index 
compared to L. semilineatus, a small member of the genus. We cannot explain why this would more important in larger species, and drawing conclusions from data applicable to only one population can be misleading (see data for $L$. semilineatus above or comments in Micco et al., 1997). We hypothesize that SSD in the genus Leiocephalus usually is the product of intrasexual competition among males for mates (Darwin, 1871; Hendrick and Temeles, 1989). Because diets did not differ significantly between sexes in this study, the competitive niche hypothesis (Selander, 1966; Schoener, 1967) probably can be discounted. However, the degree of SSD in other species of Leiocephalus varies geographically, at least in the Bahamian Archipelago (e.g., Smith, 1992), and intraspecific niche divergence (sensu Shine, 1989) may be responsible in some instances (see also Censky, 1996).

\section{Population Size}

At the Puerto Alejandro site, population size estimates (Heckel and Roughgarden, 1979) of our eight plots ( $1152 \mathrm{~m}^{2}$ total area) were $25.0 \pm 3.7$ for Leiocephalus semilineatus and $5.3 \pm 1.0$ for $L$. schreibersii, indicating that the two species were sympatric at approximately a 5:1 ratio. Using the Schnabel method, we estimated a 3:1 ratio (26.0 \pm 0.2 for $L$. semilineatus and $8.3 \pm 0.4$ for $L$. schreibersii). The microhabitat of the eight plots appeared to be more suitable for $L$. semilineatus than for $L$. schreibersii, as none included the more open, treeless areas of the study site where the latter species was observed most frequently. In contrast, we saw the most $L$. semilineatus in the plots along the road and in partially vegetated rocky areas. Only one $L$. semilineatus and one $L$. schreibersii were encountered in the elevated rocky plots that received intense sunlight and had little cover.

\section{Activity Period}

Observations while working the study plots indicated that activity began at about 0730 , peaked at about 1000 , and declined throughout the remainder of the day until dark. However, data collected along the transect did not correspond with this pattern. Some of the discrepancies may be attributed to the fact that we conducted several surveys of the transect on relatively cool, overcast days, during which lizards seemed less inclined to retreat into refugia. Powell et al. (1996) encountered a similar situation where abnormally high numbers of lizards were seen on cloudy days. In the current study, 79 lizards were encountered on 15 walks of the survey transect, with the greatest number of lizards found during a walk begun at 1245 (Figure 3 ). Activity began at about 0830 , increased until early afternoon, then declined through the afternoon. The latest sightings were at 1645 . Our single activity peak contrasted with the bimodal pattern observed by Smith (1994) in Leiocephalus psammodromus on a small cay in the Caicos Islands.

\section{Escape Behavior}

For $L$. semilineatus the mean primary and secondary response distances were $201 \pm 41$ $\mathrm{cm}(\mathrm{n}=20,45-520 \mathrm{~cm})$ and $102 \pm 16 \mathrm{~cm}(\mathrm{n}=10,20-160 \mathrm{~cm})$, respectively. For $L$. 
schreibersii the mean primary and secondary response distances were $385 \pm 105 \mathrm{~cm}$ (n $=5,270-595 \mathrm{~cm})$ and $150 \mathrm{~cm}(\mathrm{n}=1)$, respectively. These did not differ significantly from those of $L$. semilineatus (Mann-Whitney $U, Z=-0.7, p=0.51$ ). Individuals of both species moved to other perches, in which case they were approached again, or into cover (including vegetation such as bunch grass, dead agaves, and shrubs, cracks in rocks, and burrows). On many occasions, L. schreibersii seemed more difficult to approach than $L$. semilineatus. The former was more frequently found in open areas and had to run considerable distances to find shelter, whereas $L$. semilineatus frequently perched on rocks under which lizards could quickly retreat. Secondary approach distances were shorter than primaries (Mann-Whitney $U$, $Z=-2.4, p=0.015$ ). Regalado (1998) noted similar responses in Cuban Anolis.

\section{Focal Observations}

We observed most animals originally perched on rocks, twigs, tree stumps, or garbage. Others were seen under brush or on dirt berms. When lizards were approached closely, they frequently responded with head bobs and/or pushups directed at the observer.

Leiocephalus semilineatus spent the largest percentage of time perching (mean $=75.1$ $\pm 5.9 \%, 0-100 \%$ ), a qualitatively categorized "behavior" that undoubtedly including sitand-wait foraging. Perches were almost always elevated above the surrounding substrate. Lizards used rocks more frequently than any other perches (82 of 134 recorded observations, $61.1 \%$ ). Most rocks used as perches were isolated from one another but, when in piles, lizards almost always used the highest rock. We observed 32 lizards (23.9\%) on sticks and debris (including trash), 14 (10.4\%) on earthern berms along roads, four (3.0\%) on living vegetation, and only two $(1.5 \%)$ on level ground. Smith (1995) found L. psammodromus on litter (38.6\%), trees (22.8\%), bare sand $(18.5 \%)$, and rocks (11.4\%). Whether these differences reflect different preferences by the lizards or the availability of different perches is unknown.

The mean percentage of time spent interacting with conspecifics was $19.3 \pm 5.9 \%$ ( 0 $100 \%)$, time spent moving was $5.6 \pm 2.5 \%(0-80 \%)$, and time spent feeding was 0.006 $\pm 0.005 \%(0-0.17 \%)$. No correlation was found between time of day and percentage of time spent engaged in any of the four behavioral categories (Spearman test; $p>0.05$ ).

Because we made observations at different times of day, with most observations made within an hour of noon, the data may have inaccurately represented the behavior of lizards throughout an entire day. We noticed lizards basked at fully insolated sites in the morning, but moved to shaded sites or were under cover in the afternoon. During the hours when most observations were made (1130-1300 h), feeding was infrequent, possibly because the animals feed primarily at other times. Distinguishing between feeding and substrate-licking was sometimes difficult.

Interactions with other lizards constituted the second most frequently observed behavior, and primarily involved adult male-to-male and male-to-female 
interactions. Juvenile/subadult lizards were most often disregarded by adults, even when moving or basking in close proximity. Males demonstrated both moderate (headbobs and pushups) and aggressive (chasing and stealing perches) behavior toward other males. On three different occasions, different individuals that appeared to be "highly agitated" followed headbobs with a wavelike raising and lowering of the body and tail. Because we failed to observe this behavior in most interactions, we believe it is limited to circumstances involving considerable stress. A similar behavior was seen in Leiocephalus barahonensis (R.A. Sosa, pers. obs.). Male-to-female interactions were usually not aggressive and consisted primarily of headbobs, pushups, and occasional lateral wavelike movements by females. Copulation was not observed during focal studies, but mounting was seen once during an elaborate series of displays involving two males and one female.

\section{Temperature}

Mean cloacal temperatures of Leiocephalus semilineatus and L. schreibersii (Figure 4) did not differ significantly between species or among males, females, and juveniles/subadults within species, although body temperatures of females were higher than those of males and juveniles/subadults in both species. We also found no significant differences between environmental temperatures where specimens of the two species were collected. The mean difference between cloacal and substrate temperatures for $L$. semilineatus was $2.90 \pm 0.4^{\circ} \mathrm{C}\left(\mathrm{n}=21,0.2-6.1^{\circ} \mathrm{C}\right)$ and between cloacal and air temperatures was $2.61 \pm 0.32{ }^{\circ} \mathrm{C}\left(\mathrm{n}=21,0.1-6.3^{\circ} \mathrm{C}\right)$. The mean difference between cloacal and substrate temperatures for $L$. schreibersii was $7.0 \pm$ $1.5^{\circ} \mathrm{C}\left(\mathrm{n}=14,1.1-19.5^{\circ} \mathrm{C}\right)$ and between cloacal and air temperatures $4.3 \pm 0.7{ }^{\circ} \mathrm{C}(\mathrm{n}=$ $\left.14,0.3-8.5^{\circ} \mathrm{C}\right)$. Differences between $L$. semilineatus and $L$. schreibersii cloacalsubstrate temperatures (Mann-Whitney $\mathrm{U}, \mathrm{Z}=-2.54, \mathrm{p}=0.01$ ) and cloacal-air temperatures $(Z=-1.99, p=0.047)$ were significant, indicating that $L$. semilineatus maintained median body temperature closer to ambient temperature than did L. schreibersii.

\section{Reproduction}

Based on the presence of oviductal eggs or yolked ovarian follicles, clutch size of Leiocephalus semilineatus was $1-2$. Mean oviductal egg length in $L$.

semilineatus was $11.0 \pm 3.2 \mathrm{~mm}(\mathrm{n}=5,6.9-14.5 \mathrm{~mm})$, mean yolked ovarian follicle length was $3.4 \pm 2.57 \mathrm{~mm}(\mathrm{n}=3,1.9-6.4 \mathrm{~mm})$, and mean testis length was $2.3 \pm 0.4$ $\mathrm{mm}(\mathrm{n}=8,1.5-2.7 \mathrm{~mm})$. Of the eleven adult $L$. schreibersii examined, only one female had an oviductal egg $(21 \mathrm{~mm})$. Two females had enlarged oviducts but had neither eggs nor yolked ovarian follicles, suggesting that eggs had been deposited recently. Mean follicle length was $3.7 \pm 2.0 \mathrm{~mm}(\mathrm{n}=6,2.0-7.0 \mathrm{~mm})$ and mean testis length $5.0 \pm 1.4 \mathrm{~mm}(\mathrm{n}=2,4-6 \mathrm{~mm})$. No correlation was found between SVL and egg, follicle, or testis length in either species (Spearman test, L. semilineatus: SVL-egg, $Z=-$ $0.10, p=0.92 ;$ SVL-follicle, $Z=0.71, p=0.48$; SVL-testis, $Z=0.96, p=0.34 ; L$. schreibersii: SVL-follicle, $Z=1.81, p=0.07$; SVL-testis, $Z=1.00, p=0.32$ ). 
Diet

Food item numbers, volumes, frequencies, and importance values for all species are summarized in Table 1. Twenty types of prey items were identified in Leiocephalus semilineatus from the Puerto Alejandro site and 18 in L. schreibersii. In both species, ants were the food type present in the highest numbers, volumes, and frequency. In $L$. semilineatus, coleopteran larvae ranked second in each category. In L. schreibersii, miscellaneous hymenopterans ranked second in volume, and coleopteran larvae ranked second in numbers and frequency. The largest single prey item in $L$. semilineatus was a millipede with a displacement of $0.04 \mathrm{ml}$ found in an adult male. In L. schreibersii, the largest single prey item was a spider with a displacement of $0.04 \mathrm{ml}$, found in an adult female.

At the Baní site, spiders had the highest importance value in the diet of Ameiva lineolata and ants were most important in the diet of Leiocephalus semilineatus. The largest prey item in A. lineolata was an orthopteran with a volume of $0.35 \mathrm{ml}$ found in an adult female. In $L$. semilineatus, the largest prey item was an orthopteran with a displacement of $0.70 \mathrm{ml}$ found in an adult male.

We found no significant differences in total diet (based on importance values) between Leiocephalus semilineatus and L. schreibersii at Puerto Alejandro (MannWhitney $U, Z=-0.21, p=0.83$ ); between $A$. lineolata and $L$. semilineatus at the Baní site $(Z=-0.37, p=0.71)$; between $L$. semilineatus from the Puerto Alejandro and Baní sites $(Z=-1.08, p=0.28)$; or between males, females, and juveniles within a species (Friedman test, Puerto Alejandro L. semilineatus, $\mathrm{df}=2, \mathrm{c}^{2}=0.58, \mathrm{p}=0.75 ; L$. schreibersii, df $=2, c^{2}=2.03, p=0.36$; Baní $L$. semilineatus, $d f=2, c^{2}=0.46, p=$ 0.80; . lineolata, $\mathrm{df}=2, \mathrm{c}^{2}=1.00, \mathrm{p}=0.61$ ).

Standardized niche breadths (B) for Leiocephalus semilineatus from the Puerto Alejandro site were 0.19 (females, 0.26 ; males, 0.33 ; juveniles/subadults, 0.30 ), for $L$. schreibersii 0.20 (females, 0.24 ; males, 0.16 ; juveniles/subadults, 0.48 ), for $L$. semilineatus from the Baní site 0.32 (females, 0.32 ; males, 0.25 ; juveniles/subadults, 0.41), and for Ameiva lineolata 0.31 (females, 0.34; males, 0.75; juveniles/subadults, $0.50)$. Decreasing values indicate increasing specialization; with its relatively low niche breadth value, $L$. semilineatus should be considered a specialist. However, we believe the lizards are opportunistic feeders, feeding primarily on ants only because of their abundance in the area. Schoener et al. (1982) described Leiocephalus from the Bahamas as "very catholic" based on the diversity of food taken. However, they also noted a correlation between increasing body size and herbivory. This could explain the paucity of plant material taken by $L$. semilineatus, but contradicts the complete absence of plants in the stomach contents of $L$. schreibersii.

Dietary niche overlap values between species and sites are summarized in Table 2. Groups with high overlap values share resources, whereas groups with little overlap have different feeding habits. In Leiocephalus schreibersii, diets of individuals of similar size (females and juveniles) had higher overlap values than those of individuals 
dissimilar in size (males to females and males to juveniles) whose diets presumably differed because of size-related feeding differences. The overlap between $L$.

semilineatus and $A$. lineolata at Puerto Alejandro was low, probably a consequence of differing foraging modes. In contrast, overlap between $L$. semilineatus and our sample of $L$. schreibersii at Puerto Alejandro was high, indicating that individuals of the former species competed with smaller individuals of the latter species for many of the same food resources.

\section{Resource Partitioning}

The ratio of Leiocephalus schreibersii to L. semilineatus seemed constant throughout the day, indicating that the two species did not partition resources temporally. We also did not find consistent evidence of prey partitioning. However, spatial partitioning occurred. Leiocephalus schreibersii was more common in open areas and $L$. semilineatus in rocky, vegetated areas. In addition, burrows of $L$. semilineatus were almost exclusively on slopes, whereas those of $L$. schreibersii were more common on level ground.

\section{SUMMARY}

Although Leiocephalus semilineatus is the smallest member of the genus, it is relatively representative. It uses the sit-and-wait foraging strategy typical of Leiocephalus. Although SSD varies geographically, its absence in one population is consistent with a trend within the genus for smaller species to exhibit less SSD than larger forms. The diet of this species qualifies as "catholic," but we found little evidence of herbivory. Again, species of Leiocephalus typically consume a variety of food, and the larger species are more likely to consume plants. Leiocephalus semilineatus frequently perches on rocks, sticks, or debris, either in isolation or in piles. This association provides some basis for habitat partitioning with sympatric $L$. schreibersii, which seemed to prefer more open areas, and with Ameiva lineolata. The latter is commonly seen in the same areas as $L$. semilineatus, but it rarely utilizes elevated perches and forages actively on the ground around and under the rocks and debris from which $L$. semilineatus surveys its surroundings. Daily activity peaked around midday, in contrast with bimodal patterns observed in congeners, but this may merely reflect local conditions and may vary geographically, even within species.

\section{ACKNOWLEDGMENTS}

Elizabeth E. Cast, Matthew E. Gifford, Katarzyna Grasela, Andrew J. Hardwick, Laura Perdomo, Yanerys M. Ramos, Kimberly R. Schneider, Susan M. Sifers, and Melissa L. Yeska helped in the field. Michael Hampton contributed to data analysis. Richard Glor, John Fauth, Rafe Brown, and especially Geoff Smith made numerous useful comments on earlier drafts of this manuscript. José Ottenwalder, United Nations Development Programme, facilitated our work in the Dominican Republic, and Gloria Santana, Departamento de Vida Silvestre, graciously issued our permit. Field work was funded by a National Science Foundation grant (DBI-9732257) awarded to RP. 


\section{LITERATURE CITED}

ALTMANN, J.

1974. Observational study of behaviour: sampling methods. Behaviour 49: $227-$ 267.

CENSKY, E. J.

1996. The evolution of sexual size dimorphism in the teiid lizard Ameiva plei: a test of alternative hypotheses. Pages 277-289 in Contributions to West Indian Herpetology: A Tribute to Albert Schwartz (R. Powell and R. W. Henderson, eds). Society for the Study of Amphibians and Reptiles Contributions to Herpetology, volume 12. Ithaca, New York.

DARWIN, C.

1871. The Descent of Man, and Selection in Relation to Sex. Reprint. Appleton, New York.

DURTSCHE, R. D., P. J. GIER, M. M. FULLER, W. I. LUTTERSCHMIDT, R. BRADLEY, C. K. MEIER, AND S. C. HARDY.

1997. Ontogenetic variation in the autecology of the greater earless lizard Cophosaurus texanus. Ecography 20: 336-346.

HECKEL, D. G. AND J. ROUGHGARDEN.

1979. A technique for estimating the size of lizard populations. Ecology 60: 966975.

HENDRICK, A. V. AND E. J. TEMELES.

1989. The evolution of sexual dimorphism in animals: hypotheses and tests.

Trends in Ecology and Evolution 4: 136-138.

HOWARD, A. K., J. D. FORESTER, J. M. RUDER, J. S. PARMERLEE, JR., AND R. POWELL.

1999. Natural history of a terrestrial Hispañiolan anole: Anolis barbouri. Journal of Herpetology 33: 702-706.

HURLBERT, S. H.

1978. The measurement of niche overlap and some relatives. Ecology 59: 6777.

JENSSEN, T. A., D. L. MARECELLINI, K. A. BUHLMAN, AND P. A. GOFORTH. 1989. Differential infanticide by adult curly-tailed lizards Leiocephalus schreiberisii. Animal Behaviour 38: 1054-1061.

LEVINS, R. 
1968. Evolution in Changing Environments: Some Theoretical Explorations. Princeton University Press, Princeton, New Jersey.

MICCO, S. M., G. J. LAHEY, R. A. SOSA, R. POWELL, E. J. CENSKY, AND J. S. PARMERLEE, JR.

1997. Natural history of Leiocephalus barahonensis (Tropiduridae) on the Península de Barahona, Hispañiola: an examination of two populations. Herpetological Natural History 5: 147-156.

MILSTEAD, W. W.

1957. Some aspects of competition in natural populations of whiptail lizards (genus Cnemidophorus). Texas Journal of Science 9: 410-447.

PIANKA, E. R. 1973. The structure of lizard communities. Annual Review of Ecology and Systematics 4: 53-74.

POWELL, R., R. W. HENDERSON, K. ADLER, AND H.A. DUNDEE. 1996. An annotated checklist of the amphibians and reptiles of the West Indies. Pages 51-93, plates 1-8 in Contributions to West Indian Herpetology: A Tribute to Albert Schwartz (R. Powell and R. W. Henderson, eds). Society for the Study of Amphibians and Reptiles Contributions to Herpetology, volume 12. Ithaca, New York.

, J. S. PARMERLEE, JR., M. A. RICE, AND D. D. SMITH. 1990. Ecological observations of Hemidactylus brooki [sic] haitianus Meerwarth (Sauria: Gekkonidae) from Hispañiola. Caribbean Journal of Science 26: 67-70.

, J. S. PARMERLEE, JR., AND D. D. SMITH.

1996. Evidence of spatial niche partitioning by a Hispañiolan lizard community in a xeric habitat. Pages 317-326 in Contributions to West Indian Herpetology: A Tribute to Albert Schwartz (R. Powell and R. W. Henderson, eds). Society for the Study of Amphibians and Reptiles Contributions to Herpetology, volume 12. Ithaca, New York.

PREGILL, G. K. 1992. Leiocephalus (Lacertilia, Iguanidae) of Hispañiola. III. Leiocephalus schreibersii, L. semilineatus, and L. pratensis. Journal of Herpetology 24: 39-63.

RAND, A. S. 1964. Ecological distribution in anoline lizards of Puerto Rico. Ecology 45: 745752.

REGALADO, $R$. 
1998. Approach distance and escape behavior of three species of Cuban Anolis (Squamata, Polychrotidae). Caribbean Journal of Science 34: 211217.

ROUGHGARDEN, J.

1995. Anolis Lizards of the Caribbean: Ecology, Evolution, and Plate Tectonics. Oxford University Press, New York and Oxford.

SALCEDO, R. L., J. CZERWENKA, AND E. BOLAY. 1983. Atlas de Diagramas Climáticos de la República Dominicana.

Departamento de Vida Silvestre. Seccion de Estudio y Manejo de Areas

Silvestres, Santo Domingo, República Dominicana.

SCHNABEL, Z. E.

1938. The estimation of the total fish population of a lake. American

Mathematical Monthly 45: 348-352.

SCHOENER, T. W.

1967. The ecological significance of sexual dimorphism in size in the lizard Anolis conspersus. Science 155: 474-477.

, J. B. SLADE, AND C. H. STINSON.

1982. Diet and sexual dimorphism in the very catholic lizard

genus Leiocephalus of the Bahamas. Oecologia 53: 160-169.

SCHREIBER, M. C., R. POWELL, J. S. PARMERLEE, JR., A. LATHROP, AND D. D. SMITH.

1993. Natural history of a small population of Leiocephalus schreibersii (Sauria: Tropiduridae) from altered habitat in the Dominican Republic. Florida Scientist 56: 82-108.

SCHWARTZ, A. AND R. W. HENDERSON.

1991. Amphibians and Reptiles of the West Indies: Descriptions, Distributions, and Natural History. University of Florida Press, Gainesville.

SELANDER, R. K.

1966. Sexual dimorphism and differential niche utilization in birds. Condor 68: 113-151.

SHINE, R.

1989. Ecological causes for the evolution of sexual dimorphism: a review of the evidence. Quarterly Review of Biology 64: 419-461.

SMITH, G. R. 
1992. Sexual dimorphism in the curly-tailed lizard, Leiocephalus psammodromus. Caribbean Journal of Science 28: 99-101.

1994. Observations on activity in two lizards (Anolis scriptus and Leiocephalus psammodromus). Bulletin of the Maryland Herpetological Society 30: 120-125. 1995. Observations on perch use in two lizards (Anolis scriptus and Leiocephalus psammodromus). Herpetological Journal 5: 285-286.

AND J. B. IVERSON.

1993. Reproduction in the curly-tailed lizard Leiocephalus psammodromus from the Caicos Islands. Canadian Journal of Zoology 71: 2147-2151. 